\title{
Estimation and Evaulation of Collagen Fibres as Stromal Componment in Various Grades of Oral Squamous Cell Carcinoma Using Picrosirius Red Stain under Polarised Microscope
}

\author{
Manjushree Nayak ${ }^{1}$, Jayanta Kumar Panda ${ }^{2}$, Sudha Smruti Mishra ${ }^{3}$, Bijay Kumar Das ${ }^{4}$ \\ ${ }^{1}$ Associate Professor, Post-graduate Department of Pathology, S.C.B.M.C.H., Cuttack, Odisha, India \\ ${ }^{2}$ Associate Professor, Post-graduate Department of Medicine, S.C.B.M.C.H., Cuttack, Odisha, India \\ ${ }^{3}$ Post Graduate, SCB Dental College and Hospital, Cuttack, Odisha, India \\ ${ }^{4}$ Professor and Head, SCB Dental College and Hospital, Cuttack, Odisha, India
}

Corresponding Author: Jayanta Kumar Panda, Associate Professor, Dept. of Medicine, SCB Medical College, Cuttack, Email: drjayantpanda2@ rediffmail.com

Received 12 September 2019;

Accepted 05 October 2019;

Published 14 October 2019

\begin{abstract}
Oral squamous cell carcinoma (OSSC) is the 3 rd most common form of malignancy in developed countries ${ }^{[1]}$. The tumour is composed of two basic components i e, the neoplastic cells and the reactive stroma. The stromal changes which indicate the propensity of tumour cells to infiltrate and metastasise can also be used as one of the prognostic indicator ${ }^{[4,5]}$. Use of Picrosirius red (PSR) stain along with circular polarising microscope is helpful to detect spread of malignancy and guides the treatment plan and assess prognosis ${ }^{[11]}$. The present study is aimed to analyse the various aspects of collagen fibres in relation with the different grades OSSC. 30 patients of OSCC of various grades and 10 cases of normal mucosa were evaluated and data analysed statistically using sigma scan pro image analysis software(SPSS).

Observation: Thirty patients (male-19 and female -11) of OSCC of age group 47-60 years were analysed. There were 14 well differentiated (WDSCC), 12 moderately differentiated (MDSCC) and 4 poorly differentiated (PDSCC) cases. When examined under polarising microscope majority $(85.7 \%$ ) of WDSCC and $41.67 \%$ of MDSCC showed reddish orange (RO) collagen fibres whereas in PDSCC (50\%) showed green yellow (GY) collagen fibres which is statistically significant $(\mathrm{P}=0.02)$.In WDSCC $57.14 \%$ and in MDSCC 50\% had swirl(S) arrangement whereas in PDSCC $50 \%$ had crosss hatchet $(\mathrm{CH})$ and bundle arrangement. This is again statistically significant $(\mathrm{P}=0.031)$. While examining the orientation of collagen fibres in WDSCC 71.43\% and in MDSCC, $83.33 \%$ had parallel orientation whereas in PDSCC 75\% showed non parallel orientation. This orientation is statistically significant (p.008). On comparing the nature of birefringence maximum cases of WDSCC (85.71\%) and MDSCC (83.33\%) revealed strong birefringence whereas in PDSCC 75\% exhibited weak. (statistically significant p.001).

Conclusion: PSR stain under polarising microscope is an adjunct to the routine staining for studying stromal changes. The colour, arrangement, orientation \& birefringence changes reflect its gradual shift from WDSCC to PDSCC and may help as a diagnostic and prognostic tool in OSCC.
\end{abstract}

Keywords: Collagen Fibres, Picrosirius Red Stain, OSCC

\section{Introduction}

Oral cancer represents the third most common form of malignancy in developing countries while in developed countries it is the eighth most common form of cancer. It is more common in the males accounting for $95 \%$ of all oral malignant lesions. ${ }^{[1]}$ Squamous cell carcinoma is defined as a malignant epithelial neoplasm exhibiting squamous differention characterised by the formation of keratin and or the presence of intercellular bridges. ${ }^{[2]}$ The tumour is composed of two basic components of which the neoplastic cells constitute the parenchyma while the other component in the form of reactive stroma chiefly the connective tissue supports the cell. ${ }^{[3]}$ Most studies in oncology focus on the tumour grade and stage, lymphnode metastasis and therapeutic response. Extra cellular matrix $(\mathrm{ECM})$ changes which indicate the propensity of tumour cells to infiltrate and metastasise can also be used as one of the prognostic indicators ${ }^{[4,5]}$. The tumour cells produce collagen fibres which serve as an effective barrier that the neoplastic cells must cross for the process of invasion ${ }^{[6,7]}$. Many markers are now available to study the tumour stroma interface and the ECM, but morphologic detection on Haematoxylin and Eosin (H and E) and special stain for connective tissue fibres is cost effective and can be 
used to advise the surgeon regarding the propensity for invasion and metastasis and hence to plan for the surgery accordingly ${ }^{[8]}$. Taking the above factors into consideration, analysis and evaluation of collagen as a stromal component holds reasonably predictive feature to determine the severity of tumour. Hence the present study will outline with a special emphasis on the changes in the stromal tissue subject to the invasion rather than reading the parenchymal tissue alone unlike the conventional diagnostic procedure. Picrosirius red staining method in combination with polarising microscopy appear to be the most suitable method to visualise collagen fibres with high contrast ${ }^{[9,10]}$. Collagen is known to show positive birefringence ${ }^{[11]}$. While analysing the various grading systems proposed by many authors the Broder's grading system is found to be more relevant to the present study in the way that the various modes of invasion of malignant tissue into the underlying connective tissue zone is directly favoured by the response of the stromal changes. The present study aims to analyse the various aspects of collagen fibres in relation with different grades of OSCC using combination of picrosirius red stain and circularly polarized microscope and to know the specificity and distribution of collagen fibres in oral squamous cell carcinoma in using a simple and reproducible histochemical method.

\section{Aim and objective}

1. To study and analyse the stromal collagen fibres in different grades of OSCC and observe their spatial arrangement using picrosirius red stain under circular polarising microscope.

2. To find an observable stromal change with the progression of the disease.

3. To compare the pattern and distribution of collagen fibres in various grades of OSCC.

\section{Material \& Method}

\section{Source of data}

The materials used in the study were the following

(1) Paraffin embedded biopsy specimen of oral squamous cell carcinoma and normal mucosa.(2)Soft tissue microtome,(3) Xylene,(4) Weigerts haematoxyline, (5) picrosirius red, (6) Haematoxylin and Eosin (7) Research microscope (model LM-523525) along with circular polarizer attachment.

\section{Reagents for picrosirius red staining}

(1) Weigerts from haematoxylin A, (2) Weigerts from haematoxylin B (3) Sirius red diluents, (4) Sirius red diluents, (5) Acetic Solution

Working solution 1 was prepared before use by mixing 1 and 2 .

Working solution 2 was prepared by mixing 3 and 4 till it is dissolved. It can be used within 6 month.

\section{Methodology}

Sample collection: In the present study paraffin embedded blocks of histologically diagnosed cases of oral squamous cell carcinoma of different grades(well differentiated, moderately differentiated and poorly differentiated) were retrieved from the archives of the department of oral pathology and microbiology of SCB dental college and Hospital, Cuttack, Odisha. All the cases selected for the study fulfilled the required norms and regulations. The human subjects chosen for this work voluntarily consented to be part of the study after they had been explained about the purpose of the same.

Ethical clearance: The study was approved by institutional Ethical Committee of SCB Medical College and Hospital, Cuttack.

A total of 30 cases of various grades using Broder's criteria and 10 cases of normal mucosa were evaluated between 1st January 2015 and 31st December 2015. The tissue specimens were categorized as test group and control group. Only the specimens with adequate connective tissue thickness were taken for the study.

Study Method: Sections obtained for the study were first stained with Haematoxylin and Eosin using standard staining procedure and then graded according to Broder's Criteria. After histopathological confirmation, additional sections were further subjected to staining with picrosirius red stain and were observed under polarising microscope.

Study Design: Cross sectional retrospective study.

Inclusion criteria: Incisional and excisional biopsies of conventional primary oral squamous cell carcinoma Age group of 30-80 years.

Site: alveolo-buccal complex and buccal mucosa.

Exclusion certaria: Recurrent cases of OSCC, Secondary or distant metastatic cases of oral squamous cell carcinoma. Presences of any systemic or local collagen disorder.

Control sample: Normal oral mucosal samples were obtained from the pericoronal tissue of patients who had under gone surgery for impacted third molar.

Analysis: The section was analysed using a research microscope (mode - LM -52- 3525) with polarized illumination. All the sample were analysed by two observers to check inter observe variability and the data was computed, Kappa test was performed and it showed reliability between the two observers.

\section{Observation}

There were thirty (30) patients of oral squamous cell carcinoma. The mean age of patients with well differentiated, moderately differentiated and poorly differentiated carcinoma were 47.35, 58 and 60.75 years respectively. Anova test shows no significant difference in the mean age among three groups. (Table 1) The male: female ratio was 19:11.There was no significant difference in sex distribution of these groups and the study groups were sex matched. (Table 2) Table 3 depicts the comparison of polarising colors of collagen fibres observed in the three grades of OSCC. These was a significant difference in the polarising colors observed in the three grades of OSCC $(\mathrm{P}=0.02)$. The collagen fibre alignment in normal mucosa and in picrosirius red stain is shown in image No 1 and 2. Images 3, 4 and 5 depicts the different polarising colors of collagen fibres in different grades of OSCC. Table 4 describes the histopathological correlation of collagen fibres arrangement in three grades of OSCC. There was significant difference between the arrangement of collagen fibres between three groups $(\mathrm{P}=0.031)$. The image 6,7 and 8 show the different types of arrangement of collagen fibres in different grades of OSCC. Table 5 compares the orientation of collagen fibres observed in the three grades of OSCC under polarising microscope There was a significant difference in the orientation of collagen fibres between these three groups $(\mathrm{P}=0.031)$. Image 9 and 10 show the different types of orientation of collagen fibres in different grades of OSCC $(\mathrm{P}=0.001)$. Table 6 compares the nature of birefringence of collagen fibres in the three grades of OSCC under polarising microscope. It showed a significant difference in the nature of birefringence of collagen fibres in the three grades of 
OSCC (P=0.001).Image 11,12 and 13 show the nature of

birefringence of collagen fibres in different grades of OSCC.

Table -1: Comparison of mean age of study group

\begin{tabular}{|c|c|c|c|c|c|}
\hline & $\begin{array}{l}\text { Well } 1 \text { differentiated } \\
\text { Carcinoma }(n=14)\end{array}$ & $\begin{array}{l}\text { Moderately differentiated } \\
\text { carcinoma }(\mathrm{n}=12)\end{array}$ & $\begin{array}{l}\text { Poorly differentiated } \\
\text { carcinoma }(n=4)\end{array}$ & F value & $\mathbf{P}$ \\
\hline Mean age (in yrs) & 47.35 & 58 & 60.75 & \multirow[t]{2}{*}{4.54} & \multirow[t]{2}{*}{0.10} \\
\hline S.D & 10.277 & 8.984 & 14.795 & & \\
\hline
\end{tabular}

Table 2: Comparison of sex distribution of study group

\begin{tabular}{|c|c|c|c|c|c|}
\hline Sex & $\begin{array}{l}\text { Well differentiated } \\
\text { carcinoma }(n=14)\end{array}$ & $\begin{array}{c}\text { Moderately differentiated } \\
\text { carcinoma }(n=12)\end{array}$ & $\begin{array}{c}\text { Poorly differentiated } \\
\text { carcinoma }(n=4)\end{array}$ & Chi-square & $\mathbf{P}$ \\
\hline Male n $(\%)$ & $10(71.42)$ & $6(75)$ & $3(75)$ & \multirow[t]{2}{*}{1.54} & \multirow[t]{2}{*}{0.46} \\
\hline Female $\mathrm{n}(\%)$ & $4(28.57)$ & $6(50)$ & $1(25)$ & & \\
\hline
\end{tabular}

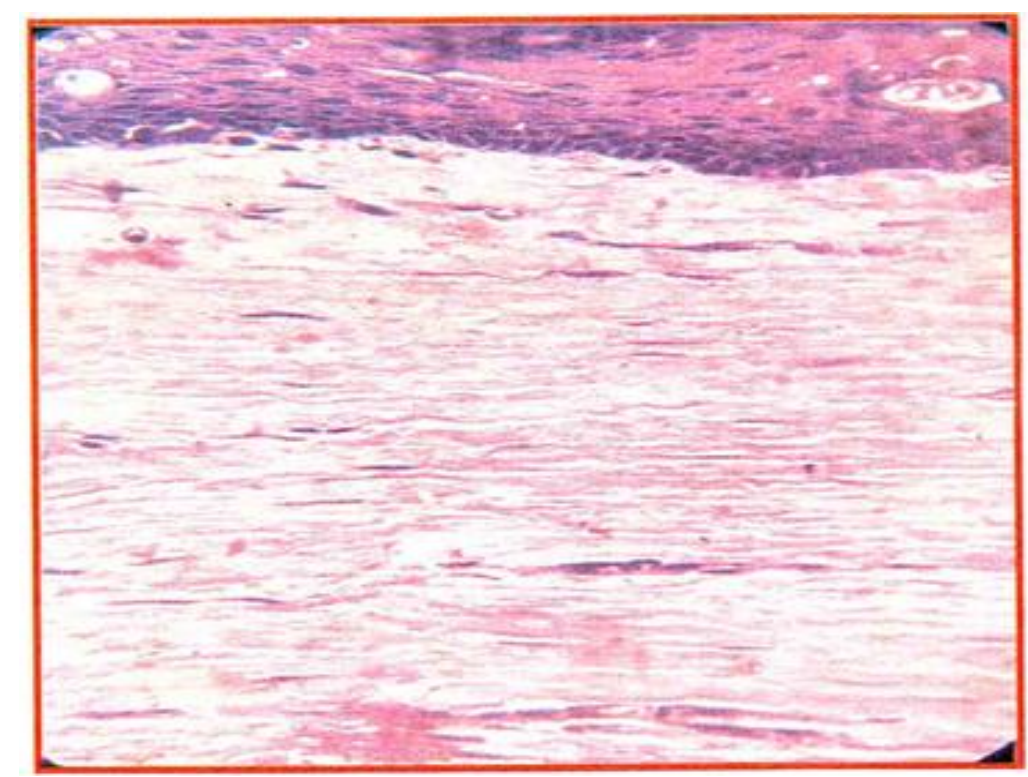

Figure 1: HE stain of normal mucosa (100x Magnification)

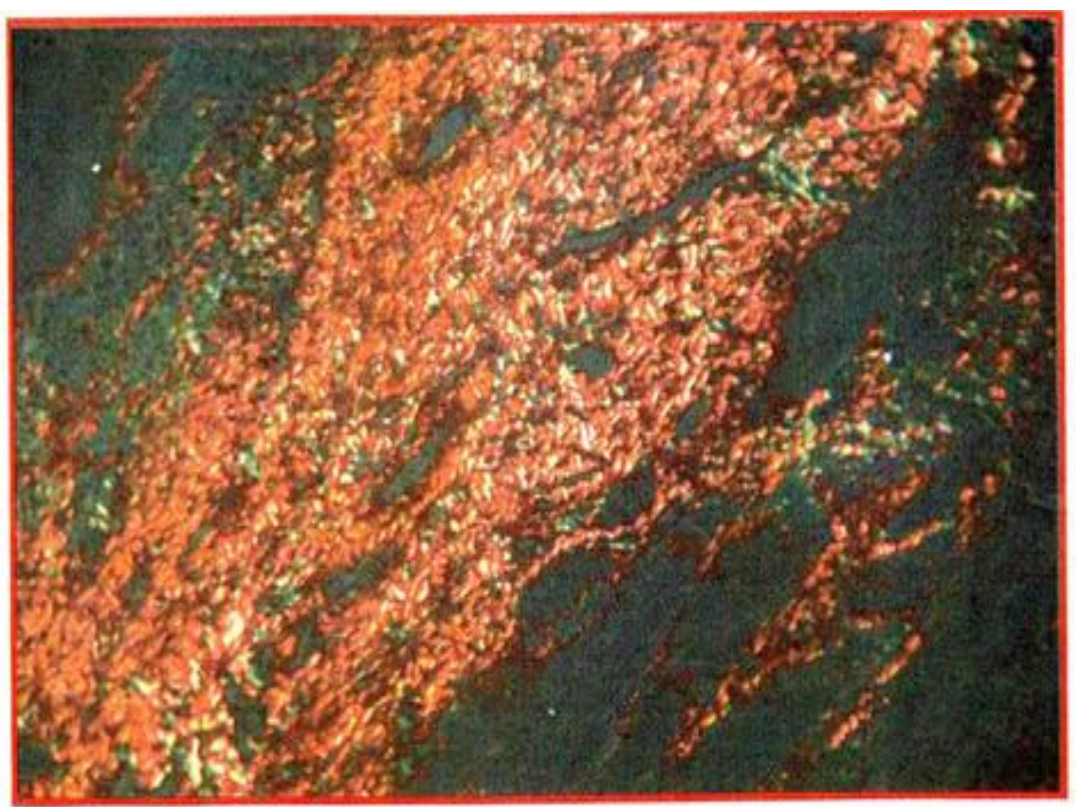

Figure 2: Collagen fiber alignment in normal mucosa in picrosirius red stain

Table 3: Comparison of polarising colours of collagen fibers observed in the three grades of OSCC

\begin{tabular}{|c|c|c|c|c|c|}
\hline $\begin{array}{l}\text { Polarising } \\
\text { colours }\end{array}$ & $\begin{array}{l}\text { Well differentiated } \\
\text { carcinoma }(n=14)\end{array}$ & $\begin{array}{l}\text { Moderately differentiated } \\
\text { carcinoma }(n=12)\end{array}$ & $\begin{array}{l}\text { Poorly differentiated } \\
\text { carcinoma }(n=4)\end{array}$ & Chi square & $\mathbf{P}$ \\
\hline GY n (\%) & $0(0)$ & $2(16.67)$ & $2(50)$ & \multirow[t]{3}{*}{10.85} & \multirow[t]{3}{*}{0.02} \\
\hline Yon (\%) & $2(14.29)$ & $5(41.67)$ & $1(25)$ & & \\
\hline RO n (\%) & $12(85.71)$ & $5(41.67)$ & $1(25)$ & & \\
\hline
\end{tabular}


Table 4: Histopathological co-relation of collagen fibres arrangement in the three grades of OSCC under polarising microscope

\begin{tabular}{|c|c|c|c|c|c|}
\hline Arrangement & $\begin{array}{l}\text { Well differentiated carcinoma } \\
\qquad(n=14)\end{array}$ & $\begin{array}{l}\text { Moderately differentiated } \\
\text { carcinoma }(n=12)\end{array}$ & $\begin{array}{l}\text { Poorly differentiated } \\
\text { carcinoma }(n=4)\end{array}$ & $\begin{array}{c}\text { Chi } \\
\text { square }\end{array}$ & $\mathbf{P}$ \\
\hline Bundle n (\%) & $2(14.28)$ & $2(16.67)$ & $2(50)$ & \multirow[t]{3}{*}{4.74} & \multirow[t]{3}{*}{0.031} \\
\hline Cross Hatchet n (\%) & $4(28.57)$ & $4(33.33)$ & $2(50)$ & & \\
\hline Swirl n (\%) & $8(57.14)$ & $6(50)$ & $0(0)$ & & \\
\hline
\end{tabular}

Images showing different polarising colors of collagen fibers in different grades if OSCC

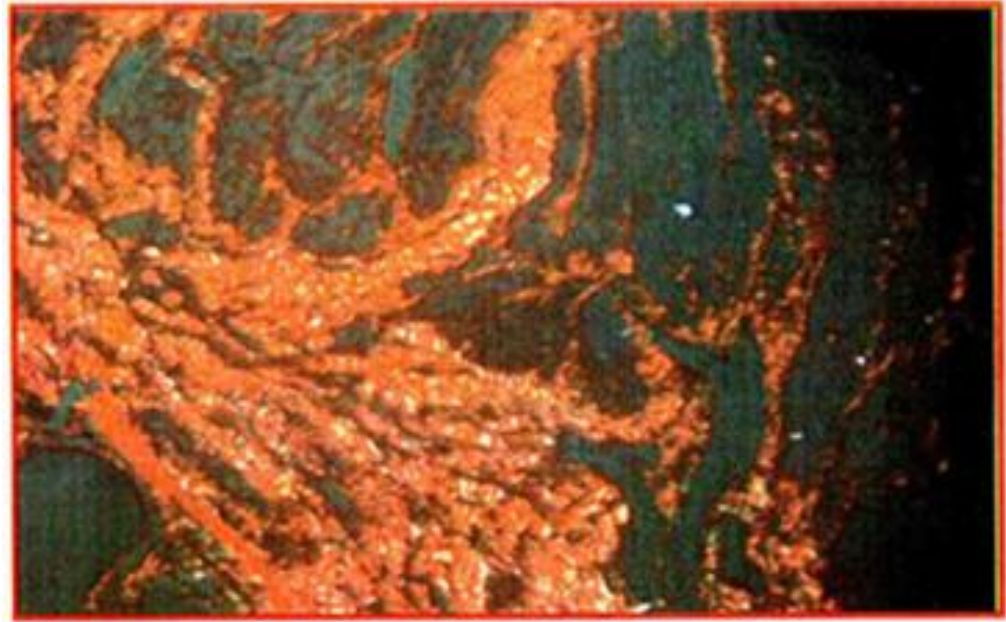

Figure 3: Reddish orange collagen fibers in WDSCC

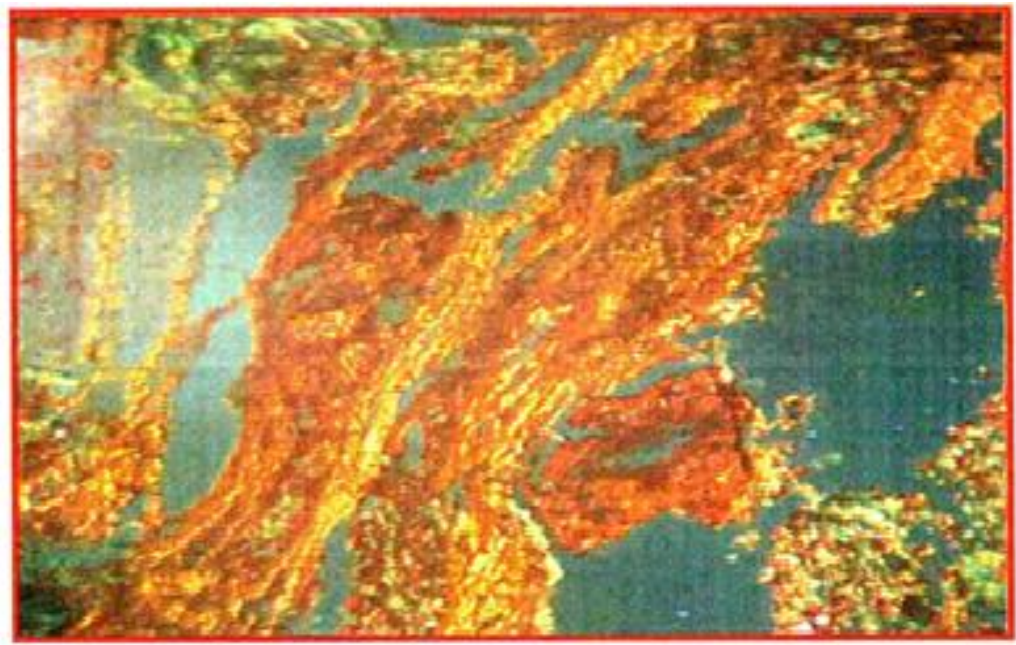

Figure 4: Yellowish orange to greenish yellow collagen fibers in MDSCC

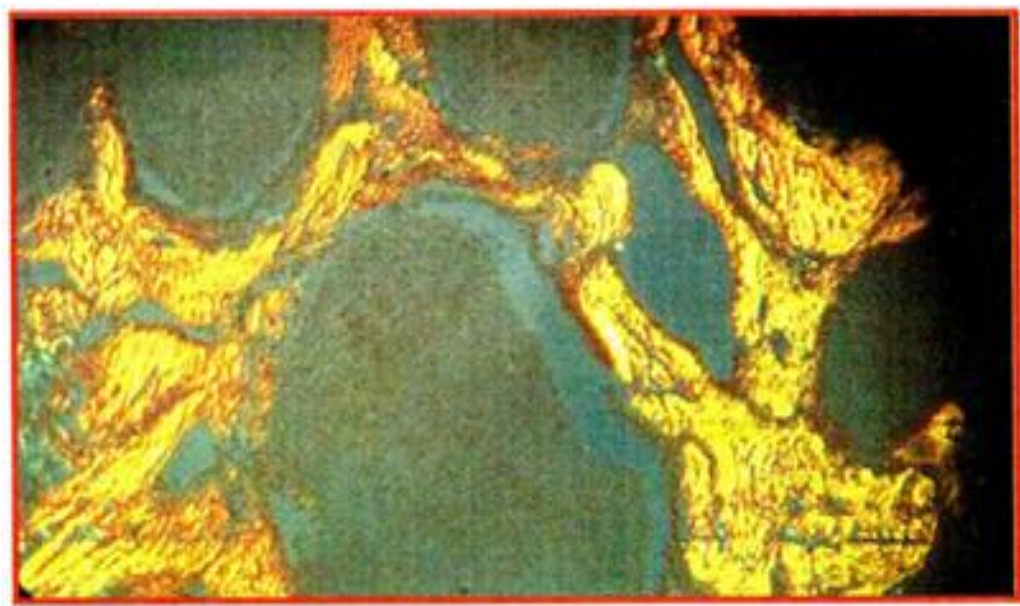

Figure 5: Greenish yellow collagen fibers in PDSCC 
Images showing the different types of arrangement of collagen fibers in different grades of OSCC

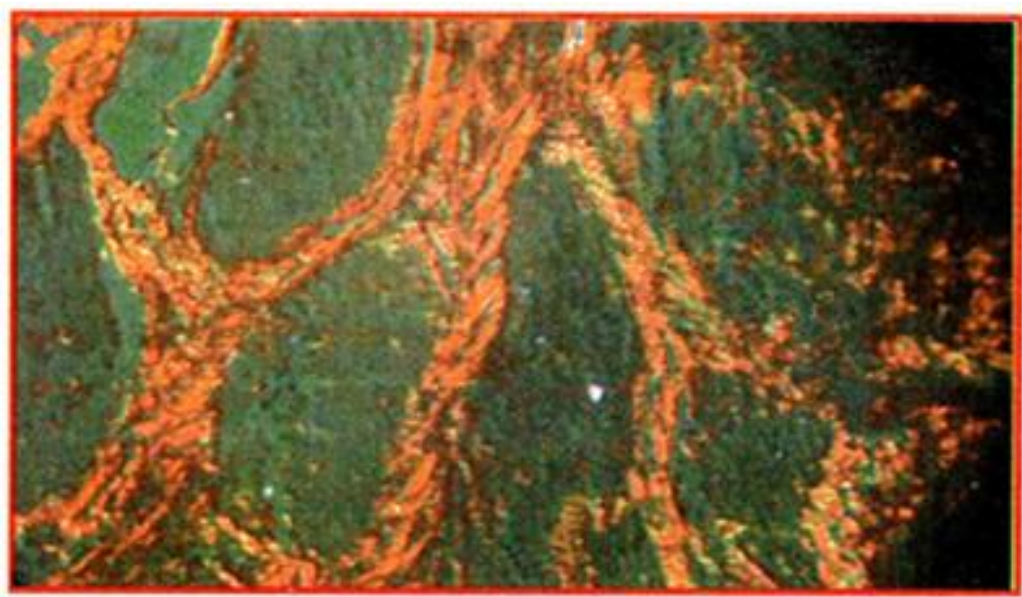

Figure 6: Swirl arrangement of collagen fibers

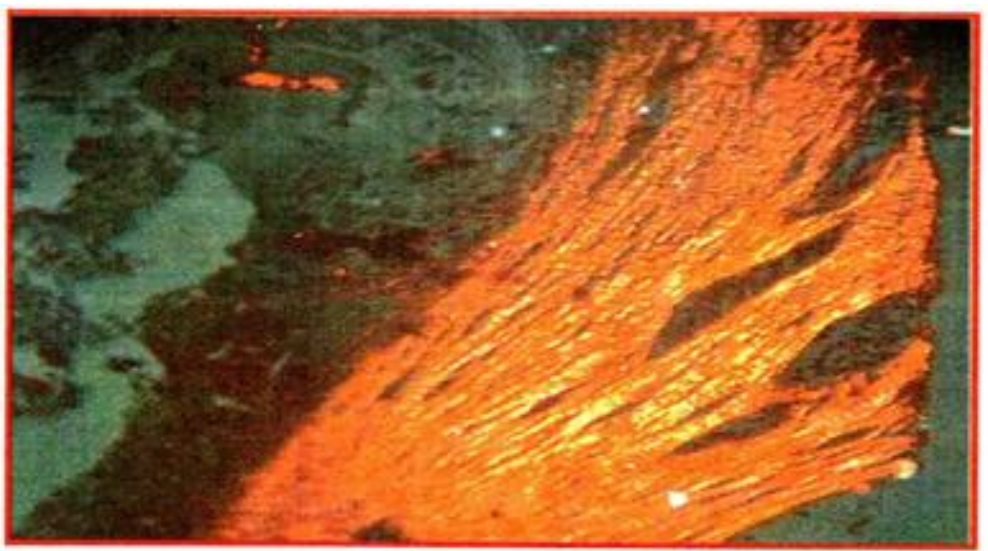

Figure 7: Bundle arrangement of collagen fibers

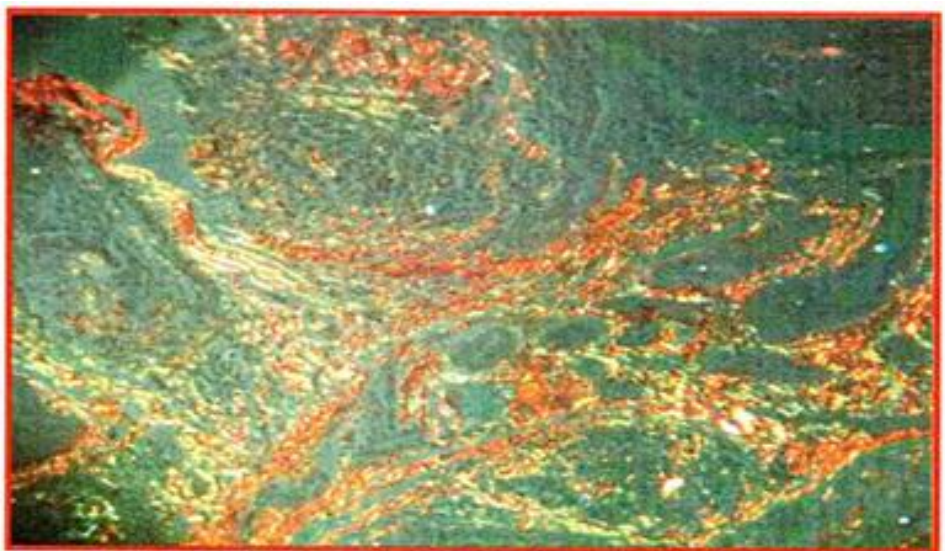

Figure 8: Cross hatchet arrangement of collagen fibers

Table 5: Comparison of the orientation of collagen fibers observed in the three grades of OSCC under polarizing microscope

\begin{tabular}{|c|c|c|c|c|c|}
\hline Orientation & $\begin{array}{l}\text { Well differentiated } \\
\text { carcinoma }(n=14)\end{array}$ & $\begin{array}{c}\text { Moderately differentiated } \\
\text { carcinoma }(n=12)\end{array}$ & $\begin{array}{l}\text { Poorly differentiated } \\
\text { Carcinoma }(n=4)\end{array}$ & $\begin{array}{l}\text { Chi- } \\
\text { square }\end{array}$ & $\mathbf{P}$ \\
\hline $\begin{array}{l}\text { Parallel } \\
\mathrm{n}(\%)\end{array}$ & $10(71.43)$ & $10(83.33)$ & 1. $(25)$ & \multirow[t]{2}{*}{4.88} & \multirow[t]{2}{*}{0.008} \\
\hline Non Parallel n (\%) & $4(28.57)$ & $2(16.67)$ & $3(75)$ & & \\
\hline
\end{tabular}

Table 6: Comparison of nature of birefringency of collagen fibers in the three grades of OSCC under polarizing microscope

\begin{tabular}{|c|c|c|c|c|c|}
\hline $\begin{array}{c}\text { Nature of } \\
\text { Birefringency }\end{array}$ & $\begin{array}{l}\text { Well differentiated } \\
\text { carcinoma }(n=14)\end{array}$ & $\begin{array}{l}\text { Moderate differentatied } \\
\text { Carcinoma }(n=12)\end{array}$ & $\begin{array}{l}\text { Poorly differentatied } \\
\text { Carcinoma }(n=4)\end{array}$ & Chi-squre & $\mathbf{P}$ \\
\hline Strongn (\%) & $12(85.71)$ & $10(83.33)$ & $\mathbf{0}(\mathbf{0})$ & \multirow{3}{*}{17.53} & \multirow{3}{*}{0.001} \\
\hline Moderate D (\%) & $2(14.29)$ & $1(8.33)$ & $1(25)$ & & \\
\hline Weak n (\%) & $0(0)$ & $1(8.33)$ & $3(75)$ & & \\
\hline
\end{tabular}


Images showing the different types of orientation of collagen fibers in different grades of OSCC

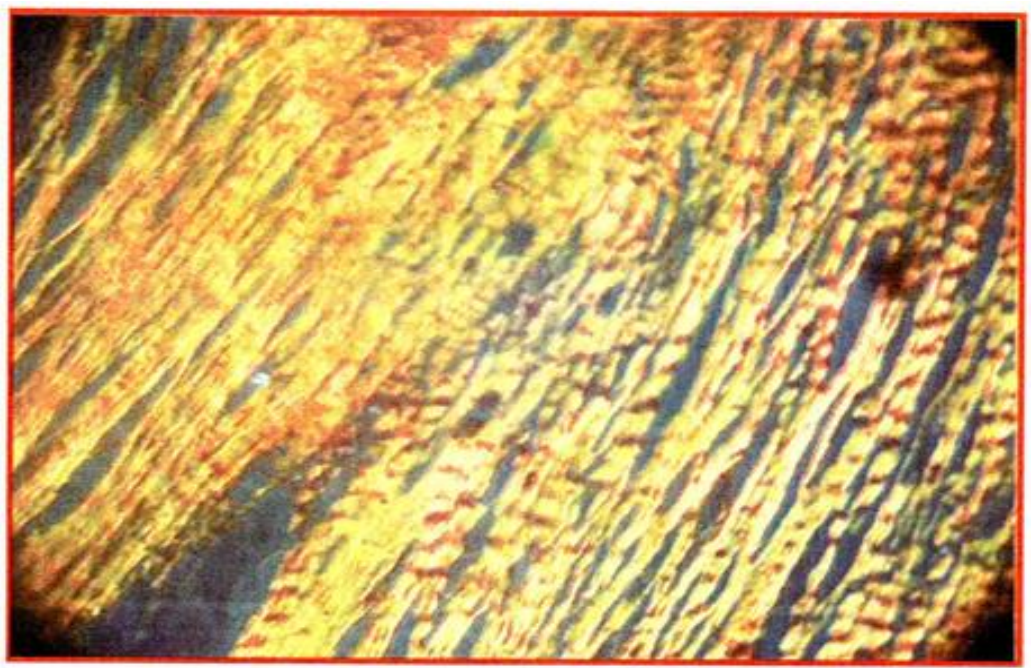

Figure 9: Parallel arrangement of collagens fibers

Images showing the nature of birefringency of collagen fibers in different grades of OSCC

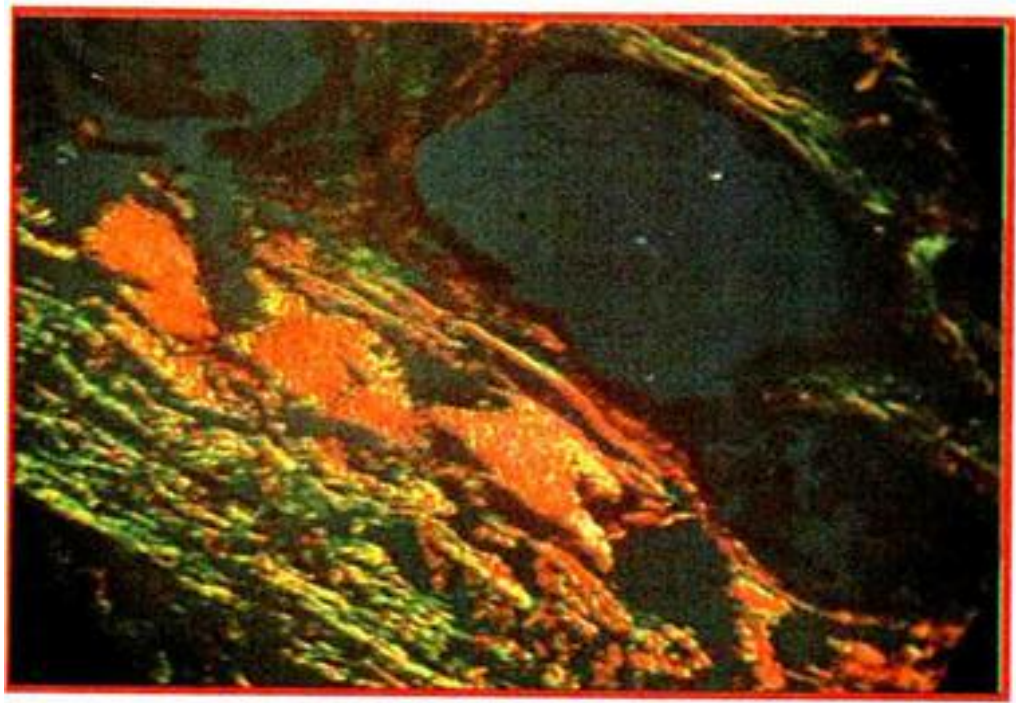

Figure 10: Strong Birefringent collagen fibers

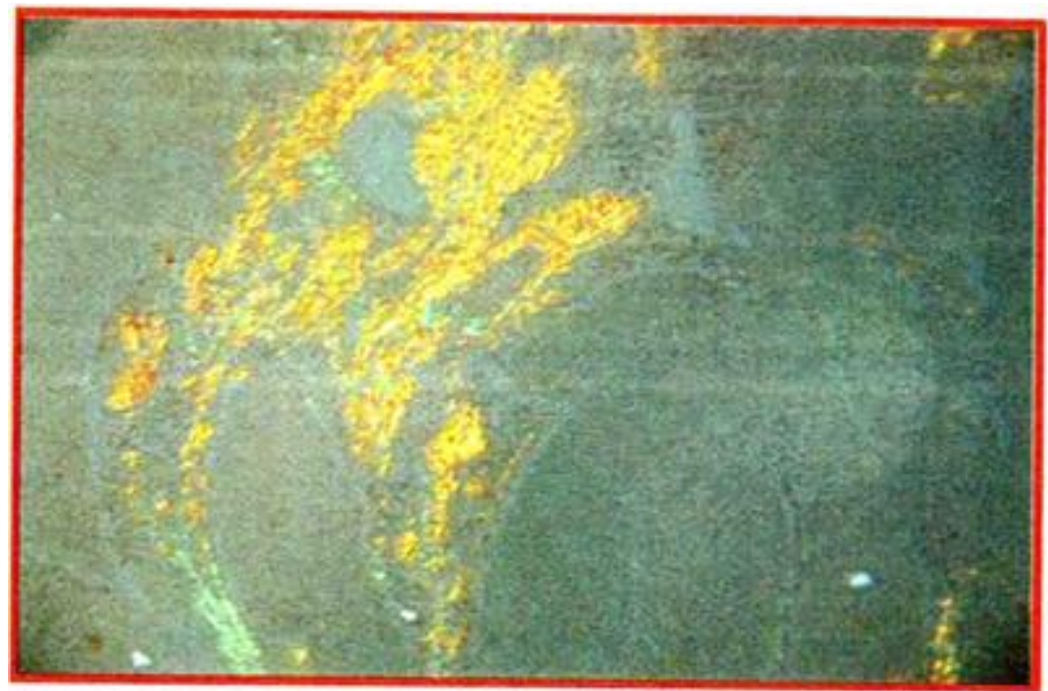

Figure 11: Moderate birefringent collagen fibers 


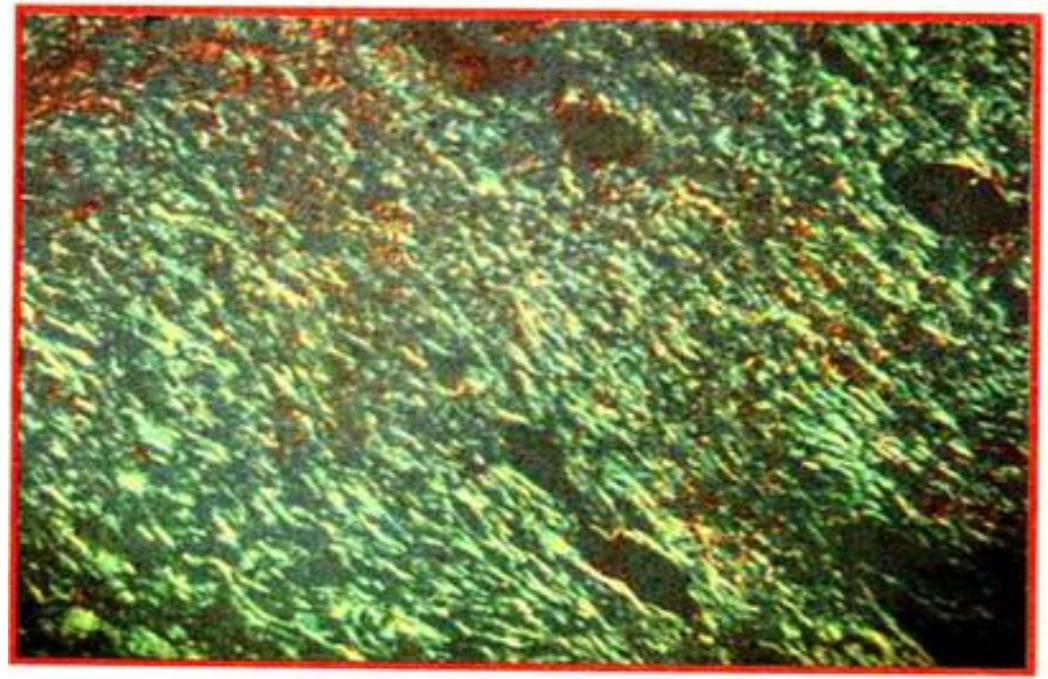

Figure 12: Weak birefringent collagen fibers

\section{Discussion}

The present study is aimed to study and analyse the stromal collagen fibres in different grades of OSCC and observe their spatial arrangement using picrosirius red staining (PSR) under circular polarizing microscope. 30 subjects were divided into three groups. The first group included 14 well differentiated squamous cell carcinoma (WDSCC) cases whereas second group included 12 moderately differentiated squamous cell carcinoma (MDSCC) cases and third group included 4 poorly differentiated squamous cell carcinoma (PDSCC) cases (table 1). The mean age of different groups were 47.35 years for WDSCC patients whereas the same for MDSCC and PDSCC were 58 and 60.75 years respectively. There was no significant difference in the mean age of different study groups. Majority of the patients were found within 4th - 6th decades of their lives which is in agreement to the observation of Syed Mukith Ur Rahaman et al in 2014.There were 19 male and 11 female patients amounting to $63.33 \%$ and $36.67 \%$ respectively. Thus it was found that the distribution of males and females appear to be more or less equal as confirmed by chi square test and hence the study groups matched with sex distribution in table 2 . Table 3 presented the distribution of study subjects as per the polarizing colours obtained by PSR staining and polarizing microscopy as observed in the three grades of oral squamous cell carcinoma. Out of 14 cases of WDSCC, majority $(85.71 \%$ ) showed reddish orange (RO) collagen fibers and yellowish orange (YO) in $14.29 \%$.In none the colour of fibers was greenish yellow (GY). In MDSCC majority (41.67\%) showed RO and YO fibers and few(16.67\%) showed GY fibers. In PDSCC majority $(50 \%)$ showed GY fibers, $\mathrm{RO}$ and YO fibers were observed in equal proportion of $25 \%$ each. Chi square test derived with $\mathrm{p}$ value $0.02(<0.05)$ confirmed such association to be statistically significant. This could be due to various growth factors and cytokines that cause proliferation of fibroblasts and ECM resulting in the formation of thick mature collagen. ${ }^{[12]}$ It may be noted that thick mature collagen normally exhibits RO colour ${ }^{[13,14,15]}$. In addition to this the polarization colours of collagen fibres in the fibrotic process have shown that during maturation of fibres the proteoglycan content changes and dehydration occurs which increases the number of cross-links and stainable side groups; thus the diameter of collagen fibres grows markedly ${ }^{[16,17,18]}$. Similar observation were also reported in the literature by Bhari baranesha Manjunatha et al in 2015. This indicated that in different grades of OSCC, there is gradual change in birefringence ranging from $\mathrm{RO}$ to $\mathrm{YO}$ and eventually to GY. However another study done by Martin GB et al suggested some changes in the collagen but did not report colour variation as the grades of OSCC progressed ${ }^{[12,14]}$. Such thick, tightly packed collagen fiber in WDSCC, exhibiting RO polarising colour maybe considered as a natural biological barrier to prevent infiltration as well as metastasis and is considered to be a factor for better prognosis. There is a shift in polarising colours of collagen fibers in our study in MDSCC and PDSCC from YO to GY. This could be explained by the fact that as OSCC progresses, there is increased collagenolytic activity. The altered fibroblast phenotype produces altered collagen $^{[14,15]}$. Previous studies (Szendroi) have shown that during tumorigenesis, collagen type I (thick) is synthesised which gives RO hue when stained with PSR which is seen in WDSCC. As the grade progresses from well to moderate to poor, there is a shift in collagen from type I(thick) to type III(thin) suggesting that as the carcinoma progresses the surrounding stroma co-evolves active state through continuous tumor stroma interaction ${ }^{[19,20]}$. According to Junqueira et al and Montes et al. the color change can be attributed to the carcinogenic events, pathological break down of the matrix by the tumor cells, abortive stroma, there by pomoting tumor progression ${ }^{[21]}$.

In the present study table 4 shows the relationship of the type of fiber arrangement in different grades of OSCC. Out of 14 cases of WDSCC, majority (57.14\%) had swirl(S) arrangement of collagen fibers, few (14.28\%) showed bundle(B) arrangement. Similarly, out of 12 MDSCC cases majority (50\%) had swirl arrangement of collagen fibres, few (16.67\%) had bundle arrangement. Out of 4 cases of PDSCC, majority (50\%) had cross hatchet $(\mathrm{CH})$ and bundle arrangement of collagen fibers. Swirl arrangement was absent. The correlation between the different types of arrangement of collagen fibers in the three grades of OSCC showed that the association was statistically significant $(\mathrm{p}$ value $=0.031$ ). Similar result was also observed by Bhari Sharanesha Manjunatha, Aditi Agrawal, Vandana Shah in their study in $2015^{[22]}$. We presume that the intertwining of collagen fibers as seen in swirl arrangement tightens the fibers thereby delivering toughest resistance to tumour cells to invade. Whereas the collagen fibers in moderate and poorly differentiated OSCC are more disorganized due to increased stromal destruction that may enhance movement of tumor cells towards blood and lymphatic vessels ${ }^{[22]}$.

Table 5 of our present study examined the orientation of the collagen fibers in relation to the tumor islands in the three grades of OSCC. Out of 14 cases of WDSCC, majority (71.43\%) showed parallel orientation and $28.57 \%$ showed non parallel orientation. 
Out of 12 cases of MDSCC, majority(83.33\%) showed parallel orientation of collagen fibers and $16.67 \%$ showed non parallel orientation. Out of 4 cases of PDSCC majority(75\%) showed non parallel orientation of collagen fibers and $25 \%$ showed parallel orientation. The correlation showed that the association was statistically significant ( $p$ value 0.008 ). Similar result was also observed in the studies conducted by Bhari Sharanesha Manjunatha, Aditi Agrawal, Vandana Shah in 2015 $5^{[22]}$. Although literature is silent about the difference in the orientiation pattern of collagen fibers, it may be presumed that as WDSCC shows the presence of type I collagen fibers, it has a more organized parallel orientation as compared to moderate and poorly differentiated carcinoma which are composed of immature type III fibers existing in a meshwork, reticular or non parallel orientation.

On comparing the nature of birefringency (table 6) of the collagen fibers in the three grades of oral squamous cell carcinoma both the observers noted that in maximum patients there was strong birefringence of collagen fibers in well differentiated $(85.71 \%)$ and moderately differentiated $(83.33 \%)$ oral squamous cell carcinoma whereas in poorly differentiated carcinoma, majority $(75 \%)$ exhibited weak birefringence. Chi square test was done and the association was found to be statistically significant with $\mathrm{p}$ value 0.001. This is also supported in the literature in the studies conducted by Bhari Sharanesha Manjunatha, Aditi Agrawal, Vandana Shah in $2015^{[22]}$. Type I collagen (thick fibers) being predominantly present in WDSCC showed a strong birefringence of orange, red and yellow colours while PDSCC is composed of mainly type III collagen(thin fibrillar) showed weak birefringence of green by polarizing microscope. Although literature has not explained the difference of such intensity of the stromal collagen fibers in the vaious grades of OSCC, we presume that the reason for such variation in their intensity could be due to physical and biochemical nature of the collagen fibers in the advancement of the histological grades of carcinoma.

\section{Conclusion}

In the present study, observable collagenous changes were seen in progressive grades of OSCC. We have demonstrated that the combination of PSR with polarization microscopy is a powerful tool for its structural analysis. The observations of the present study indicate that picrosirius red (PSR) stain is an adjunct to the routine staining for studying stromal changes at the invading front of the tumour and this in turn aids in predicting tumour behaviour. The color changes reflect its gradual shift from thicker mature fibres towards thinner immature fibers in stroma during tumor progression. The present study strongly validates previous result that in differentiation of OSCC there is a change in the polarization colours of thick fibres from RO to $\mathrm{YO}$ and then to GY due to abnormal collagen production, degradation, and defective maturation which may promote neoplastic progression. In this study the significant variation in arrangement, orientation and nature of collagen (indicated by strength of birefringence), in different grades of OSCC proves increased disorganization of stroma with tumor progression which may be valuable as a diagnostic and prognostic indicator more so as a supplement to parenchymal changes. Determination of nature of collagen fiber in different grades of oral squamous cell can help for targeting the stroma for various treatment strategies. Thus, it should be supplemented with gold standard i.e., $\mathrm{H}$ and $\mathrm{E}$ and molecular markers on a larger sample including the tumor invasion front to extrapolate this knowledge. Further research with larger sample size is required in this direction.

\section{Limitations of the study}

Although the PSR staining in combination with PM is a precise, effective and specific technique to study collagen, still as with all methods, it suffers from some limitations too.

- Few collagen fibers that appear crimped or wavy may appear dark irrespective of rotated microscope stage, resulting in underestimating and analysing their volume

- The green colour, despite its specificity for thin collagen fiber/ type III fibers may also appear in immature type I fiber, raising a lot of conundrums.

\section{Bibliography}

1. Dantas DD, Ramos CC, Costa AD, Souza LB, Pinto LP. Clinical- pathological parameters in squamous cell carcinoma of the tongue. Brazilian dental journal. 2003 Jun;14(1):22-5.

2. Rajendran R, Sivapathasundaram B. Shafer's textbook of Oral Pathology. 5th edition, Delhi: Elsevier India 2008.

3. Venigella A, Charu S. Evaluation of collagen in different grades of Oral Squamous cell Carcinoma by using the Picrosirius red stain-A Histochemical study. Journal of Clinical and Diagnostic Research 2010; 4:3444-3449.

4. Ritchie AC. Boyd's text book of pathology, Lea and Fabiger, Philadelphia, 1990,Page 266.

5. Agrawal U, Rai H,Jain AK. Morphological and ultrastructural characteristics of extracellular matrix changes in oral squamous cell carcinoma. Indian J Dent Res 2011; 22: 16-21.

6. Nerenberg PS, Salsas-Escat RA, Stultz CM. Collagen-a necessary accomplice in the metastatic process. Cancer Genomics-Proteomics. 2007 Sep 1;4(5):319-27.

7. Li HX, Zheng JH, Fan HX, Li HP, Gao ZX, Chen D. Expression of ava6 integrin and collagen fibre in oral squamous cell carcinoma: association with clinical outcomes and prognostic implications. Journal of Oral Pathology and Medicine. 2013 Aug 1;42(7):547-56.

8. Doshi NP, Shah SA, Patel KB, Jhabuawala ME Histological grading of oral cancer: a comparison of different systems and their relation to lymph node metastasis. National Journal of Community Medicine. 2011;2(1):136-42.

9. Rich L, Whittaker P. Collagen and picrosirius red staining: a polarized light assessment of fibrillar hue and spatial distribution. Braz J Morphol Sci. 2005 Jun;22(2):97-104.

10. Noorlander ML, Melis P, Jonker A, Van Noorden CJ. A quantitative method to determine the orientation of collagen fibers in the dermis. Journal of Histochemistry \& Cytochemistry. 2002 Nov1;50(11): 1469-74.

11. Montes GS, Junqueira LC. The use of the Picrosiriuspolarization method for the study of the biopathology of collagen. Memorias do Institute Oswaldo Cruz. 1991;86:1-1.

12. Martins GB, Reis SR, Silva TM. Collagen type I expression in squamous cell carcinoma of the oral cavity. Pesqui Odontol Bras. 2003;17(1):82-88. 
13. Singh HP, Shetty DC, Wadhwan V, Aggarwal P. A quantitative and qualitative comparative analysis of collagen fibers to determine the role of connective tissue stroma on biological behavior of odontogenic cysts: A histochemicalstudy. National journal of maxillofacial surgery. 2012 Jan 1;3(1):15.

14. Daley WP, Peters SB, Larsen M. Extracellular matrix dynamics in development and regenerative medicine. Journal of cell science. $2008 \mathrm{Fe} \mathrm{1;121(3):255-64.}$

15. Fuentes B,Duaso J, Droguett D, Castillo C,Donoso W, Rivera C, B, Kemmerling U. Progressive extracellular matrix disorganization in chemically inducedmurine oral squamous cell carcinoma. ISRN Pathology 2012 Aug $29 ;, 2012$.

16. Prabhu SR, Wilson DF, Daftary DK, Johnson NW. Oral diseases in the tropics, Oxford University Press, New Delhi, 1993, Page 429.

17. Ghosh S, Munshi HG, Sen R, Linz McGillem LA, Goldman RD, Lorch J, et al. Loss of adhesion regulated proteinase production is correlated with invasive activity in oral squamous cell carcinoma. Cancer 2002;95:2524 33
18. Dayan D, Hiss Y, Hirshberg A, Bubis JJ, Wolman M. Are the polarization colors of picrosirius red-stained collagen determined only by the diameter of the fibers? Histochemistry. 1989 Nov 1;93(1):27-9.

19. Szendroi M, Vajta G, Kovacs L, Schaff Z, Lapis K. Polarization colours of collgaen fibers: A sign of collagen production activity in fibrotic process. Acta Morphol Hung. 1984;32:47-55.

20. Kawashiri S, Tanaka A, Noguchi N, Hase T, Nakaya H, Ohara T, Kato K, Yamamoto E. Significance of stromal desmoplasia and myofibroblast appearance at the invasive front in squamous cell carcinoma of the oral cavity. Head \& neck. 2009 Oct 1;31(10): 1346-53.

21. Junqueira LC, Cossermelli W, Brentani R. Differential staining of collagens type I, II and III by Sirius Red and polarization microscopy. Archivum histologicum Japonicum $=$ Nihon soshikigaku kiroku. 1978 Jun;41(3):267-74.

22. Manjunatha BS, Agrawal A, Shah V. Histopathological evaluation of collagen fibers using picrosirius red stain and polarizing microscopy in oral squamous cell carcinoma. Journal of cancer research and therapeutics. 2015 Apr 1; 11 (2):272. 